\title{
The Nramp (Slc11) proteins regulate development, resistance to pathogenic bacteria and iron homeostasis in Dictyostelium discoideum
}

\author{
Barbara Peracino, Simona Buracco and Salvatore Bozzaro* \\ Department of Clinical and Biological Sciences, University of Turin, AOU S. Luigi, 10043 Orbassano, Italy \\ *Author for correspondence (salvatore.bozzaro@unito.it) \\ Accepted 22 August 2012 \\ Journal of Cell Science 000, 1-11 \\ (c) 2013. Published by The Company of Biologists Ltd \\ doi: $10.1242 / j c s .116210$
}

\begin{abstract}
Summary
The Dictyostelium discoideum genome harbors two genes encoding members of the Nramp superfamily, which is conserved from bacteria (MntH proteins) to humans (Slc11 proteins). Nramps are proton-driven metal ion transporters with a preference for iron and manganese. Acquisition of these metal cations is vital for all cells, as they act as redox cofactors and regulate key cellular processes, such as DNA synthesis, electron transport, energy metabolism and oxidative stress. Dictyostelium Nramp1 (Slc11a1), like its mammalian ortholog, mediates resistance to infection by invasive bacteria. We have extended the analysis to the nramp 2 gene, by generating single and double nramp1/nramp 2 knockout mutants and cells expressing GFP fusion proteins. In contrast to Nramp1, which is recruited to phagosomes and macropinosomes, the Nramp2 protein is localized exclusively in the membrane of the contractile vacuole, a vesicular tubular network regulating cellular osmolarity. Both proteins colocalize with the V- $\mathrm{H}^{+}$-ATPase, which can provide the electrogenic force for vectorial transport. Like nramp1, nramp2 gene disruption affects resistance to Legionella pneumophila. Disrupting both genes additionally leads to defects in development, with strong delay in cell aggregation, formation of large streams and multi-tipped aggregates. Single and double mutants display differential sensitivity to cell growth under conditions of iron overload or depletion. The data favor the hypothesis that Nramp1 and Nramp2, under control of the V-H ${ }^{+}$-ATPase, synergistically regulate iron homeostasis, with the contractile vacuole possibly acting as a store for metal cations.
\end{abstract}

Key words: Dictyostelium discoideum, Iron transporter, Nramp1, Nramp2, V-H+-ATPase, Iron homeostasis, Cell growth, Development, Legionella pneumophila, Bacterial infection, Phylogenesis

\section{Introduction}

The natural resistance-associated macrophage protein (Nramp) or solute carrier 11 (Slc11) family includes functionally related proteins defined by a conserved hydrophobic core of ten-twelve transmembrane domains. All members are proton-coupled transporters that facilitate absorption of divalent metal ions, including $\mathrm{Fe}^{2+}, \mathrm{Mn}^{2+}, \mathrm{Zn}^{2+}, \mathrm{Co}^{2+}$ and $\mathrm{Cd}^{2+}$ (Courville et al., 2006; Forbes and Gros, 2001; Nevo and Nelson, 2006;). In mammals two homologs are found, Nramp1 (Slc11a1) and Nramp2 (Slc11a2 or DMT1). Nramp1 is found exclusively in macrophages and granulocytes, is localized in vesicles of the endosomal pathway and recruited to the phagosomal membrane upon phagocytosis (Canonne-Hergaux and Gros, 2004; Gruenheid et al., 1997). By controlling divalent metal concentrations, Nramp1 regulates the intracellular replication of pathogens. In mice, naturally occurring or experimentally induced mutations in Nramp1 cause susceptibility to infections by invasive bacteria. Mutations in humans may genetically predispose an individual to diseases, including tuberculosis, leishmaniasis and autoimmune diseases (Courville et al., 2006; Li et al., 2011; Malik et al., 2005; Nevo and Nelson, 2006; Taylor and Kelly, 2010; Velez et al., 2009; Wick, 2011). In contrast to Nramp1, Nramp2 is localized in the plasma membrane of cells in several tissues, particularly the apical membrane of intestinal and renal epithelial cells, and is the major transferrin-independent iron uptake system in mammals (CanonneHergaux et al., 1999; Courville et al., 2006; Theil, 2011). Alternative splicing gives rise to Nramp2 isoforms, which are mainly found in recycling endosomes, and are required in combination with Nramp1 for efficient iron recycling (LamYuk-Tseung and Gros, 2006; Soe-Lin et al., 2010). Mutations in Nramp2 are responsible for microcytic anemia and serum and hepatic overload (Iolascon and De Falco, 2009). Genetic studies in rodents have shown that Nramp2 is essential for survival and a critical threshold of the protein is necessary to protect against disorders of iron and manganese homeostasis (Fleming et al., 1997; Gunshin et al., 2005).

Nramp proteins are widely distributed in eukaryotes and prokaryotes (Courville et al., 2006). Based on sequence analysis Richer et al. (Richer et al., 2003) have distinguished prototypical Nramps, present in amoebae, yeasts, plants and invertebrates, from archetypical Nramps, which can be also found in these species but are the only homologs present in vertebrates, including mammalian Nramp1 and 2. In Gram-positive and Gram-negative bacteria, the Nramp superfamily is represented by the proton-dependent manganese transporter (MntH) family (Papp-Wallace and Maguire, 2006; Richer et al., 2003).

The genome of the social amoeba Dictyostelium discoideum harbours two nramp genes. The first gene product that was 
characterized was called Nramp1, as it displayed all the properties of the mammalian ortholog (Peracino et al., 2006). Similarly to mammalian Nramp1, Dictyostelium Nramp1 was expressed in vesicles of the endolysosomal pathway, was recruited to phagosomes, and its inactivation affected susceptibility to infection by Legionella and Mycobacterium. The protein was found to be required for $\mathrm{H}^{+}$-dependent iron export in isolated phagosomes (Peracino et al., 2006), favoring the notion of iron depletion from the phagosome, as originally suggested for mammalian Nramp1 (Forbes and Gros, 2001). Although $\mathrm{Fe}^{2+}$ in phagolysosomes can produce hydroxyl radicals via Fenton reaction, thus potentially killing bacteria, depletion of the iron pool from the phagosome deprives pathogenic bacteria of metal ions that are critical for their survival. Invasive bacteria, such as Legionella pneumophila, Mycobacterium tuberculosis or Salmonella enterica serovar Typhimurium are known to absorb large amounts of iron, while at the same time they are resistant to oxygen radicals (Henard and Vazquez-Torres, 2011; Johnson and Wessling-Resnick, 2012; Kortman et al., 2012; Moalem et al., 2004; Robey and Cianciotto, 2002; Slauch, 2011). Recently, we also showed that L. pneumophila hinders recruitment of the V$\mathrm{H}^{+}$-ATPase, but not Nramp1, in the Legionella-containing vacuole in a process apparently involving inhibition of phosphatidylinositol-3-phosphate formation. By avoiding colocalization of $\mathrm{V}-\mathrm{H}^{+}$-ATPase with Nramp1 in the same vesicle, Legionella neutralizes the proton-driven iron export via Nramp1, and may even turn the protein activity to its advantage (Peracino et al., 2010).

Nramp1 is one of a few genes that have been implicated in Dictyostelium innate immunity against pathogenic bacteria (Bozzaro and Eichinger, 2011; Chen et al., 2007; Cosson and Soldati, 2008; Sillo et al., 2008; Steinert, 2011). Dictyostelium cells are professional phagocytes that live in the forest soil as solitary amoebae and grow by grazing on different species of bacteria (Bozzaro et al., 2008; Kessin, 2001). Depending on bacteria as the obligate source of food, Dictyostelium can also be a natural host of pathogenic bacteria, and several pathogens that only occasionally infect humans, including L. pneumophila, M. tuberculosis, Salmonella typhimurium, Neisseria meningitidis or Pseudomonas aeruginosa, have been shown to be pathogenic also for Dictyostelium (Bozzaro and Eichinger, 2011; Colucci et al., 2008; Hagedorn et al., 2009; Lima et al., 2011; Sillo et al., 2011; Steinert, 2011). The solitary Dictyostelium amoebae enter a social phase of life upon depletion of the food source. Starvation induces a developmental process, whereby cells assemble into multicellular aggregates by chemotaxis, giving rise to elongated slugs, where cells undergo differentiation into prestalk and prespore cells. After a period of migration, the slugs culminate and form fruiting bodies, each consisting of a stalk of vacuolated dead cells, bearing at the top a ball of mature spores (Kessin, 2001). During development, cells do not ingest external nutrients and are bound to recycle intracellular material, mostly by autophagy and protein degradation, for acquiring the energy and synthesizing all the cellular components required for development and cell differentiation (Kessin, 2001; Otto et al., 2003).

In this paper, we have characterized the second nramp gene of Dictyostelium, thus called nramp2. The nramp2 gene is maximally expressed during the aggregation phase of development. We show that the protein is exclusively localized in the contractile vacuole network, a tubular-vesicular network regulating osmolarity (Clarke et al., 2002; Clarke and Heuser, 1997; Heuser et al., 1993). By generating single and double nramp1/nramp 2 knockout mutants, we show that Nramp2, like Nramp1, is required for resistance to invasive bacteria, and that the double mutation leads additionally to a strong delay in aggregation and to formation of multi-tipped aggregates. Under conditions of iron overload or depletion, growth of single or double $\mathrm{KO}$ mutants is differentially affected, suggesting that the Nramp proteins regulate synergistically iron homeostasis.

\section{Results \\ Characterization and developmental expression of the nramp2 gene}

The Dictyostelium genome contains two genes, both located in chromosome 2, with evident sequence homology to genes of the Nramp superfamily. The nrampl gene (DDB_G0276973) is the ortholog of mammalian nrampl and was characterized previously (Peracino et al., 2006; Peracino et al., 2010). The nramp2 gene (DDB_G0275815) encodes a putative integral membrane protein with 12 transmembrane domains and a $M_{\mathrm{r}}$ of $70 \mathrm{kDa}, 10 \mathrm{kDa}$ larger than Nramp1 (Fig. 1). The DNA sequence is intronless, in contrast to nramp1, which harbours an intron at position 199309. The protein sequence shares $38 \%$ identity and $75 \%$ similarity with Nramp1, and the similarity, as expected, is low in the $\mathrm{N}$ - and C-terminal outer membrane sequences (Fig. 1). Blast analysis against reference proteins placed Nramp2 within the Nramp superfamily (Fig. 2). It is phylogenetically closer to $\alpha$ proteobacteria $\mathrm{MntH}$ and to Nramp proteins from yeast, fungi and protists than to the Slc11 family, to which instead Nramp1 belongs (Fig. 2) (Richer et al., 2003). We extended this analysis to include all Nramp1 and Nramp2 homologs encoded in sequenced genomes of Dictyosteliaceae. As shown in Fig. 2, Nramp1 and Nramp2 homologs from D. discoideum, D. purpureum, D. fasciculatum, D. lacteum and Polysphondylium pallidum cluster in two relatively distinct groups. This is in sharp contrast with other lower eukaryotes, such as Chlamydomonas rheinardtii, and Saccharomyces cerevisiae, which harbor respectively 2 and 3 Nramps, forming in both cases, however, a single group (Fig. 2). Arabidopsis thaliana possesses 6 Nramps clustering in two groups, both of which are more closely related to Dictyostelium Nramp1 than Nramp2.

Whereas nrampl gene expression is higher during growth and declines upon starvation remaining at low level during development (Fig. 3) (Peracino et al., 2006), nramp2 gene expression was very low during growth, increased during the first 6 hours of development and declined after formation of tight aggregates (Fig. 3). This pattern is similar to that revealed by RNA-seq analysis, available from the Dictyostelium webpage (www.dictybase.org).

\section{Nramp2 is a resident membrane protein of the contractile vacuole}

To determine the cellular localization of Nramp2 we cloned the gene and generated a chimeric protein with green fluorescence protein (GFP) fused at the C-terminus. Nramp2(C)-GFP homogeneously labeled the membrane of the contractile vacuole (CV) network (Fig. 4A). In living cells plated on glass, the $\mathrm{CV}$ network, made of branched vesicles and tubules, is typically located near the ventral surface of the cell, and extends over a large area close to the plasma membrane, as can be better appreciated in a $3 \mathrm{D}$ reconstruction (supplementary material 


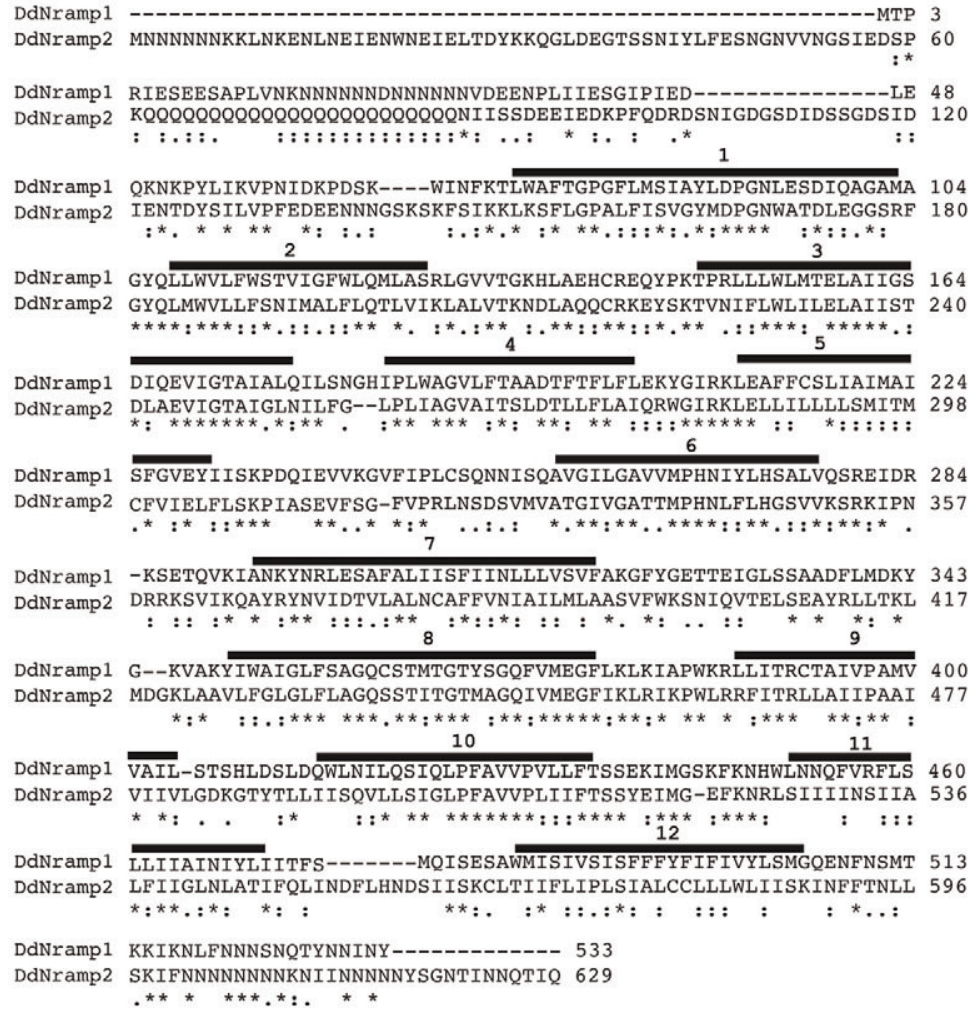

Movie 1). In higher confocal sections, no labeling was observed, except for peripheral vesicles of the $\mathrm{CV}$ adjacent to the plasma membrane (Fig. 4A). These results suggest that Nramp2 is a selective marker of the contractile vacuole. For comparison, cells expressing GFP-fused Nramp2 or Nramp1 and stained with antibodies against the vatA subunit of the $\mathrm{V}-\mathrm{H}^{+}$-ATPase are shown (Fig. 4C). The $\mathrm{V}-\mathrm{H}^{+}$-ATPase is a major component of the $\mathrm{CV}$ membrane, besides being also transiently recruited to endolysosomes (Bracco et al., 1997; Clarke et al., 2002; Gerisch et al., 2002; Peracino et al., 2006), whereas Nramp1 is not expressed in the $\mathrm{CV}$, but in the Golgi, in tiny vesicles trafficking between Golgi and plasma membrane, and transiently in endo- and phagosomes (Peracino et al., 2006). Accordingly, Nramp1 colocalized with VatA in some vesicles in upper sections, but not in the lower CV (Fig. 4B), whereas there was full colocalization of VatA and Nramp2 in the $\mathrm{CV}$, not however in VatA-positive vesicles in the upper sections (Fig. 4B).

The plasma membrane was usually devoid of Nramp2-GFP, although a clearly labeled rim all over the membrane was observed in some cells (Fig. 4C). This is very likely an artifact due to overexpression of the GFP-fused protein or to the cell adhering strongly to the substratum, as it was observed only in a minority of such cells. To further exclude in any case the possibility that Nramp2 is a plasma membrane protein, we incubated cells with TRITC-dextran for $5 \mathrm{~min}$, washed the cells and followed macropinosome formation, with particular attention to cells expressing Nramp2-GFP in the plasma membrane. When macropinocytic cups and vesicles are formed, most membrane proteins are entrapped, at least transiently, in the endocytosed membrane. We never observed Nramp2-GFP decorating TRITCfilled macropinosomes, whether or not there was any Nramp2GFP labeling of the plasma membrane (Fig. 4C,D). This is in
Fig. 1. Aminoacid sequence homology of Dictyostelium discoideum Nramp1 and Nramp2. Both sequences were aligned using the MacVector ClustalW program (Blosum matrix). Identical residues are marked by asterisks and residues with strongly or weakly similar properties with double and single points, respectively. Consensus transmembrane domains, inferred from alignment with other Nramp proteins (Czachorowski et al., 2009), are indicated by black bars. sharp contrast with Nramp1 or the VatA subunit of the vacuolar ATPase, which were transiently recruited from internal stores to TRITC-containing vesicles shortly after uptake (Fig. 4C,D) (Clarke et al., 2002; Clarke et al., 2010; Peracino et al., 2006). Cells were also incubated with neutral red, which stains acidic vesicles. As shown in Fig. 4E, no Nramp2-GFP decorated vesicles turned red, in contrast to Nramp1-GFP. Thus we conclude that Nramp2 expression is confined to the contractile vacuole, and the protein is in any case excluded from the endolysosomal pathway.

\section{Differential effects of single and double nramp gene disruption on development}

We generated single nramp 2 and double nramp1/2 KO mutants by using the Cre-loxP system (Kimmel and Faix, 2006) as detailed in supplementary material Fig. S1. The mutants were tested for growth in axenic medium and on $\mathrm{N}$-agar with Escherichia coli $\mathrm{B} / \mathrm{r}$ or for development on phosphate agar. Growth was not affected. All mutants were able to develop and form fruiting bodies, but developmental timing and fruiting body morphology were altered, particularly in the double mutant. Compared to the parental AX2 strain, the Nramp1 KO (HSB60) mutant (Peracino et al., 2006) started to aggregate at about the same time, but completed aggregation and formed tip mounds about 3 hours earlier, whereas the timing of postaggregative development was unaltered (Fig. 5). The Nramp2 KO mutant started aggregation and formed tip mounds with a 2 hour delay, but postaggregative development occurred with about the same timing as the parental strain. The double knockout mutant displayed a 6 hour delay in the beginning of aggregation till tip mound formation. Postaggregative development was also slowed down but to a lesser extent. In contrast to all other strains, the 
Method: Neighbor Joining; Bootstrap (1000 reps); tie breaking = Systematic Distance: Uncorrected ("p")

Gap sites ignored



Fig. 2. Phylogenetic relationship of Dictyostelium discoideum Nramp1 and Nramp2. Dictyostelium discoideum Nramp1 and Nramp2 sequences were compared to similar sequences using the MacVector software and performing multiple sequence alignment with the program ClustalW program (Blosum matrix). The evolutionary distance was inferred using the neighbor joining method. The percentage of replicate trees in which the associated taxa clustered together in the bootstrap test (1000 replicates) are shown next to the branches. Only a few selected sequences close to each protein are shown. Dictyostelium Nramp1 and Nramp2, together with homologs from the other Dictyosteliaceae, whose genomes have been sequenced, cluster in two different groups, the first closer to Nramp proteins of the Slc11a family and the second to yeast SMF and $\alpha$-proteobacteria MntH family.

double mutant formed larger aggregating streams on phosphate agar, which led to formation of large multitipped aggregates (Fig. 5A,B). Despite aggregate fragmentation due to multiple tip

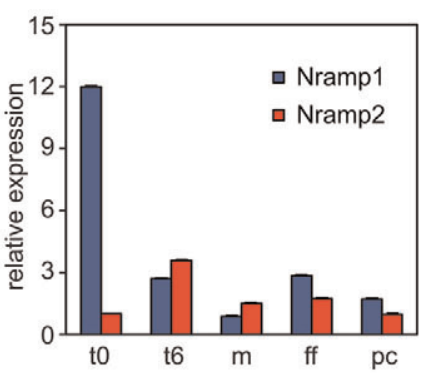

Fig. 3. Nramp1 and nrtxup2 gene expression during Dictyostelium

development. Axenically gruwing AX2 cells were washed $\left(\mathrm{t}_{0}\right)$ and starved in sorensen phosphate buffer und shaking for 6 hours ( $\mathrm{t}_{6}$ corresponding to the

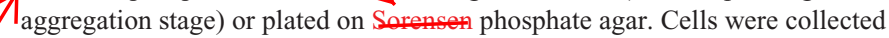
at $t_{0}$ and $t_{6}$ from shaking cultures or from agar at: (m) mound stage, (ff) first

ind (pc) preculminant stage. RNA was extracted and amplified te primers as described in Materials and Methods. Fold changes at each time point are relative to the constitutively expressed histone $\mathrm{H} 3$ gene as internal control. Mean values of three exneriments with error bars.

$$
\text { s.d. } \geqslant
$$

formation, the density of fruiting bodies was markedly reduced compared to the parental strain, and the fruiting bodies were on the average taller, though the proportion between sori and stalks was maintained (Fig. 5C,D). Expressing either Nramp1 or Nramp2-GFP in the double mutant led to rescue of both developmental timing and aggregate morphology compared to the single mutants expressing either Nramp1- or Nramp2-GFP, respectively.

\section{Differential effects of iron depletion or overload on mutant growth in minimal medium}

The Nramp proteins are proton-driven divalent metal transporters, with a preference for iron and manganese. We have shown this to apply also for Dictyostelium Nramp1 (Peracino et al., 2006), and we assume that Nramp2 also displays this function, based on the conserved protein sequence and general protein structure. As a first step to assess potential effects of nramp1 or nramp2 gene disruption on iron homeostasis, we tested the effects of iron on cell growth, by assaying growth in a minimal FM medium, containing aminoacids, vitamins, glucose and essential trace elements, previously shown to support Dictyostelium cell growth (Franke and Kessin, 1977). The FM medium contained $0.1 \mathrm{mM} \mathrm{FeCl}$. We used the same recipe, but either omitted iron or added 0.01 , 0.1 or $0.2 \mathrm{mM} \mathrm{FeCl}_{3}$. AX2 or mutant cells exponentially growing in AX2 medium were diluted 100-fold in minimal medium to an initial concentration of $3-5 \times 10^{4}$ cells per $\mathrm{ml}$, and growth was assessed under shaking over a period of 2 to 4 weeks. Despite variability in the absolute values from experiment to experiment, the trend was similar. In culture medium without added iron, only the parental AX2 cells displayed steady though slow growth, with a doubling time of about 35-40 hours, reaching a density of $1 \times 10^{6}$ cells per $\mathrm{ml}$ after $168 \pm 24$ hours (Fig. 6). The AX2 cells underwent on the average five to six duplications before reaching a plateau. The single as well as the double nrampl/nramp $2 \mathrm{KO}$ mutants grew only up to $1-2 \times 10^{5}$ cells per $\mathrm{ml}$ during the first 72 to 96 hours incubation (doubling time: 36 to 45 hours), but then stopped growing (Fig. 6). Minimal medium supplemented with 0.01 (not shown) or $0.1 \mathrm{mM}$ iron (Fig. 6) supported growth of AX2, single and double-null mutants, with all strains reaching a 


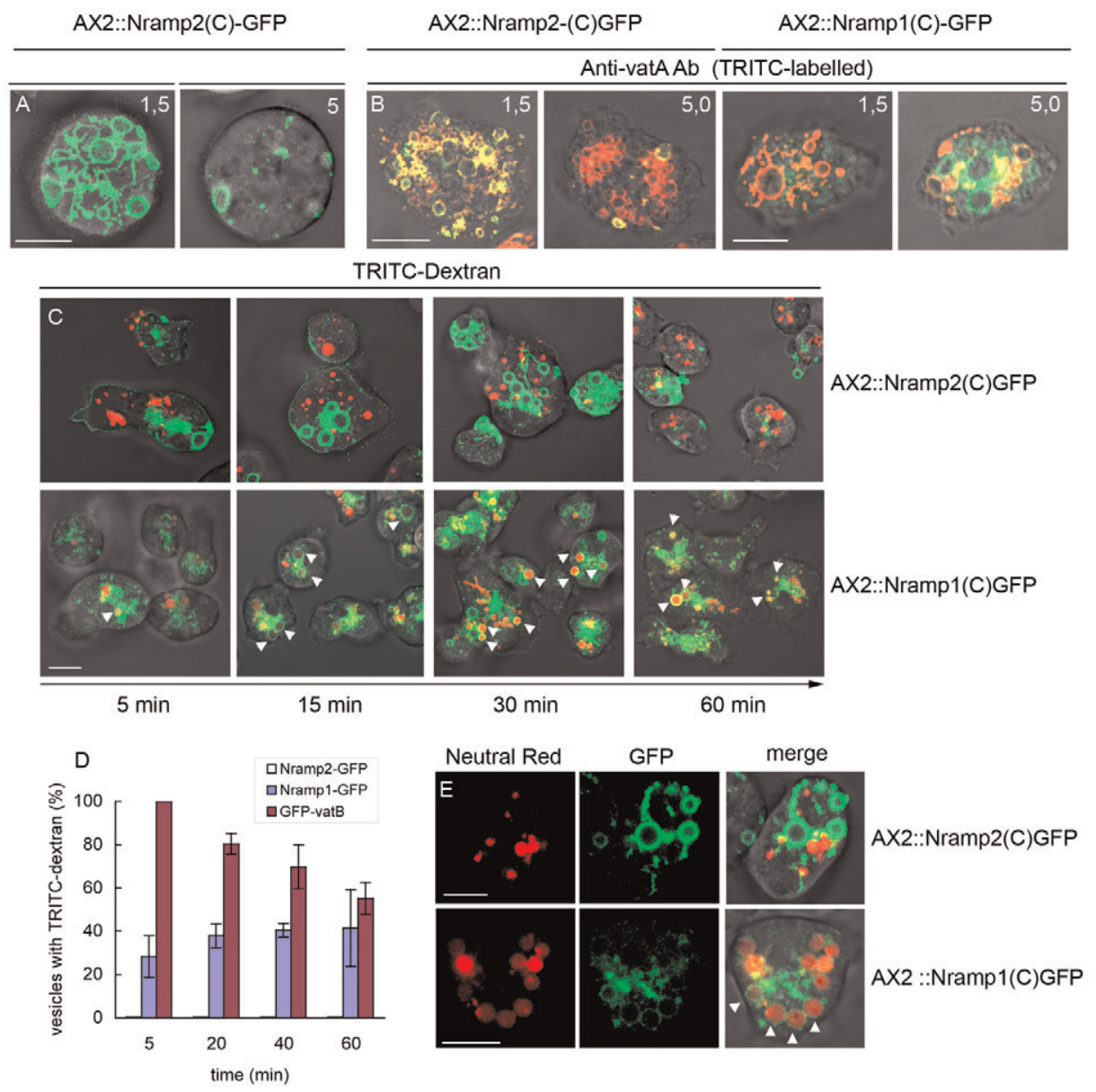

Fig. 4. Dynamics of Nramp2 and Nramp1 in cells visualized with GFP fusion protein. (A) Confocal GFP fluorescence sections merged with corresponding phase contrast through living AX2 cells expressing Nramp2(C)-GFP. The numbers indicate distance from the bottom surface of the cell. Nramp2(C)-GFP labels homogeneously vesicles interconnected by tubules and localized at the bottom region of the cell close to the substratum, which is typical of the contractile vacuole. In upper regions no labeling independent of the contractile vacuole is observed. (B) Confocal GFP fluorescence sections merged with corresponding phase contrast of methanol-fixed AX2 cells expressing either Nramp2(C)- or Nramp1(C)-GFP and costained with antibodies against the VatA subunit of the V-H ${ }^{+}$ATPase. The Nramp2-decorated vesicles in the bottom region colocalize fully with the VatA-labeling, confirming that this structure is the contractile vacuole. The $\mathrm{V}-\mathrm{H}^{+}$-ATPase subunit is also found in endolysosomal vesicles in the upper region that are not labeled by Nramp2(C)-GFP, indicating that Nramp2 is not expressed in endolysosomes. Nramp1 is not found in the contractile vacuole but in a cluster around the nucleus (Golgi) and in some vesicles colabeled with anti-VatA antibodies. Notice that methanol fixation affects in part Nramp1 and Nramp2-GFP fluorescence. Bars: $5 \mu \mathrm{m}$. (C) Confocal GFP fluorescence merged with corresponding phase contrast of living AX2 cells expressing either Nramp2(C)- or Nramp1(C)-GFP. The cells were incubated for 5 minutes with TRITC-dextran, washed and plated on glass coverslips for the indicated chase time. In contrast to Nramp1-GFP, which decorates TRITC-dextran containing vesicles (arrowheads), Nramp2-GFP fails to colocalize with TRITC-dextran, even in cells with a thin fluorescent rim of Nramp2-GFP on the plasma membrane. (D)The number of TRITC-dextran positive vesicles decorated with GFP-fused Nramp1, Nramp2 or the vatB subunit of the vacuolar ATPase was plotted over time. For each time point an average of 50 macropinosomes and 15 cells were counted. Mean values of three independent experiments with are shown (data for the VatB subunit and Nramp1 are reported from Peracino et al. (Peracino et al., 2006). (E) Confocal sections of cells expressing NrampN(C)- or Nramp2(C)-GFP incubated with neutral red, a marker of acidic vesicles. Red, green fluorescence and merge with corresponding phase-contrast are shown sequentially. Nramp2 fails to colocalize with acidic vesicles, in contrast to Nramp1, which decorates some vesicles (arrowheads). Bars: $5 \mu \mathrm{m}$. S.d.

concentration of $1 \times 10^{7}$ cells per $\mathrm{ml}$ after 168 to 196 hours incubation. At a concentration of $0.2 \mathrm{mM}$ iron, growth was inhibited in all strains, more strongly in the parental strain, but remarkably less so in the double null mutant, which was the only one able to steadily grow to $3 \times 10^{6}$ cells per $\mathrm{ml}$ after 168 hours of incubation, with an average doubling time of about 26 hours (Fig. 6). After two doublings in the first 48 hours, the Nramp2 KO mutant strain took a further 120 hours to undergo a third doubling. The Nramp1 mutant and the parental AX2 strain doubled once in the first 24 hours and then needed about 100 and
140 hours, respectively, to double a second time. Thus it appears that $0.2 \mathrm{mM}$ iron is somewhat toxic, particularly for wild type cells, whereas the double null mutant is relatively resistant. In contrast, all three mutants are much more sensitive to iron shortage than the parental strain. Cells transferred from axenic to the minimal medium contain iron released from digestion of peptone and yeast extract, and traces of iron are possibly available in the minimal medium even without added iron, thus it is not surprising that cells may undergo some duplication rounds. The results suggest nevertheless that inactivating either nrampl 
Effects of single or double gene disruption on developmental timing

\begin{tabular}{|c|c|c|c|c|c|}
\hline Strain & aggregation & tip mounds & first fingers & pre-culminants & fruiting bodies \\
\hline AX2 & 6 & 12 & 16 & 20 & 24 \\
\hline Nramp1-null & 6 & 9 & 12 & 17 & 20 \\
\hline Nramp2-null & 8 & 14 & 16 & 20 & 24 \\
\hline Nramp1/2-null & 12 & 18 & 20 & 23 & 27 \\
\hline
\end{tabular}
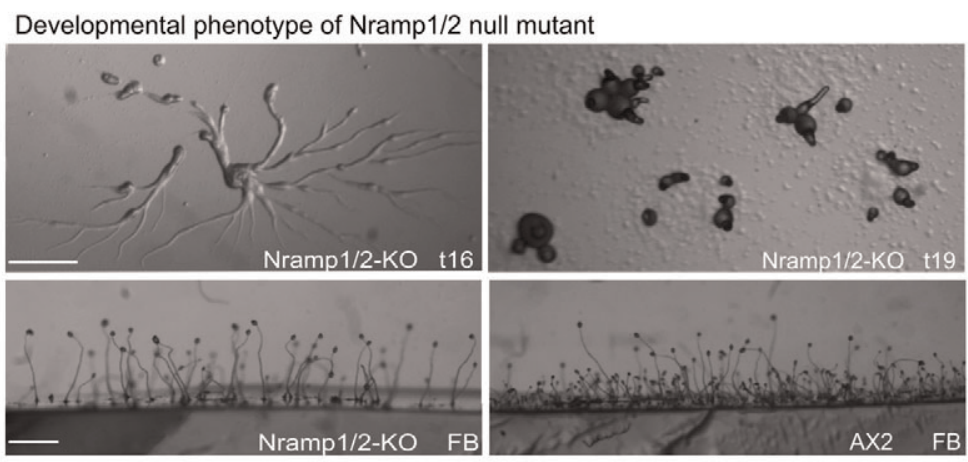

\section{Soerensen}

Fig. 5. Effects of single or double gene disruption on development. Starving cellifof parental strain and mutants were plated on nonnutrient -phosphate agar and development was monitored over time in a stereomicroscope. Top panel: the time (in hours) needed for beginning of stream formation (aggregation) or appearance of tipped aggregates, first fingers, pre-culminants and mature fruiting bodies is indicated for each mutant. (Mean of two experiments. The standard deviation was of \pm 1 hour or 2 hours for aggregation or the other developmental stages, respectively.) Bottom panels: developmental phenotype of the double mutant. (A) Cells aggregating after 12 hours starvation formed very large streams and (B) multitipped aggregates. (C) On the average taller fruiting bodies, but of reduced number, were formed, compared with (D) AX2 parental strain. Bars: $1 \mathrm{~mm}$.
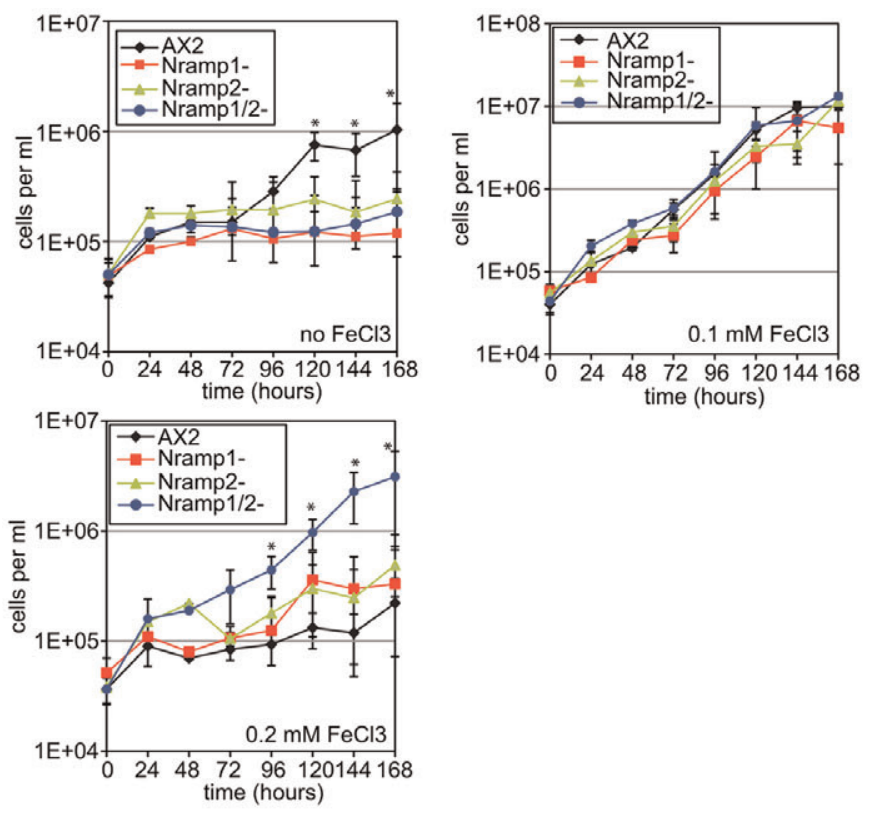

Fig. 6. Effects of single or double gene disruption on growth in minimal medium with or without $\mathrm{FeCl}_{3}$ supplementation. Exponentially growing cells were diluted in minimal medium with or without the indicated amount of iron chloride, incubated under shaking and counted for growth at the indicated times. In the absence of iron, cell growth was blocked after 1 or 2 generations in all mutants, whereas the parental AX2 strain was able to replicate for 4-5 generations, albeit very slowly. All strains grew well with $0.1 \mathrm{mM}$ iron, whereas with $0.2 \mathrm{mM}$ iron growth was depressed in all strains, but much less so in the double mutant. Mean values of at least three experiments with s.e.m. are shown. The asterisks denote significant difference (one-tailed $t$-test assuming unequal variance: $P<0.05$ ) between $\mathrm{AX} 2$ versus the double mutant in the first graph (no iron) or the double mutant versus AX2 in the third graph (0.2 $\mathrm{mM}$ iron). or nramp 2 renders the cells more sensitive than wild type cells to conditions of iron depletion. In contrast, inactivating both genes results in increased resistance to iron overload.

\section{Nramp2, like Nramp1, is required for resistance to $L$. pneumophila infection}

We showed previously that Nramp1 KO mutants were more susceptible to infection by L. pneumophila and Mycobacterium avium (Peracino et al., 2006; Peracino et al., 2010). This prompted us to test whether disrupting Nramp2 also affected resistance to invasive bacteria and whether the double mutation resulted in any additional effect. Cells were incubated with $L$. pneumophila and the rate of bacterial growth was assessed by the CFU (Colony Forming Unit) method. Despite high variation in the absolute values from experiment to experiment, the trend was similar in four different tests, as shown in the representative experiment in Fig. 7. The bacteria proliferated as well in the single nramp2- as in the nramp1-null mutant, and significantly better than in the parental AX2 strain. The double mutant behaved similarly to the single mutants up to 72 hours of infection, thereafter bacterial proliferation consistently declined. Visual examination showed, however, that at 96 hours there were clearly more extracellular bacteria in the medium containing cells of the double mutant than the single mutants, yet this finding escaped CFU detection. Since CFU measures viable bacteria, and the culture medium used for the infection assay does not support bacterial proliferation (Fig. 7) (Hägele et al., 2000; Peracino et al., 2006), these results are consistent with the hypothesis that between 72 and 96 hours of infection a higher number of cells undergo lysis in the double knockout than in the single mutants, releasing more bacteria into the medium. Because the released bacteria die in the assay medium, their higher number is not reflected in the subsequent CFU counts. Attempts to measure bacterial proliferation using GFP-labeled bacteria in fluorescence-activated flow cytometry failed, as GFP expression diminished drastically after $48 \mathrm{~h}$ of incubation. 


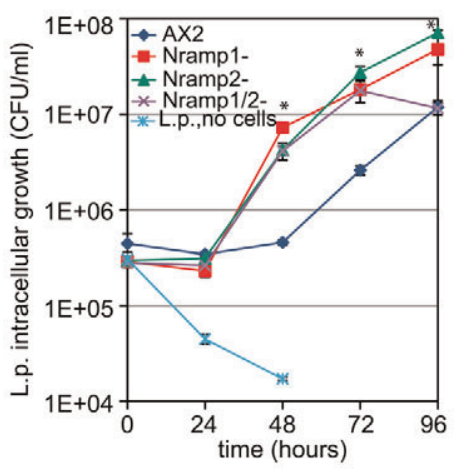

Fig. 7. Effects of single or double gene disruption on infection by Legionella pneumophila. AX2 parental strain and mutants were infected with L. pneumophila (L.p.) and intracellular growth of the bacteria was assessed by the CFU assay at the time indicated in the abscissa. In medium without cells, the bacteria do not survive. Mean values of a representative experiment in duplicate with crror bars are shown. The asterisks denote significant differences compared the parental strain for all three mutants at times 48 and 72 hours, and at time 96 hours for the Nramp1- and Nramp2-null mutant only (one-ta S.d. suming unequal variance: $P<0.05$ ). The trend in four different expcrmIIIIIs was similar, although the absolute values varied strongly from experiment to experiment.

\section{Discussion}

The strong conservation in sequence and overall transmembrane structure in the Nramp family reflects the fact that proton-driven metal cation transport is conserved from prokaryotes to higher eukaryotes (Courville et al., 2006; Czachorowski et al., 2009). Iron is vital for all cells, as it modulates the cellular redox potential and regulates key cellular processes, from electron and oxygen transport to energy metabolism and DNA synthesis (Hentze et al., 2010; Kakhlon and Cabantchick, 2002; Schaible and Kaufmann; 2004). Despite the phylogenetic conservation of the Nramp proteins, D. discoideum is unusual in that it contains to distant Nramp proteins, Nramp1 in the Slc11 family, and Nramp2 which is more closely related to yeast SMF, $C$. rheinardtii Nramp and to $\alpha$-proteobacteria $\mathrm{MntH}$ proteins. We have shown this to be true for all five Dictyostelids whose genomes have been sequenced. This is in sharp contrast with other lower eukaryotes harbouring more than one Nramp paralogs, such as $C$. rheinardtii, $S$. cerevisiae or A. thaliana, whose Nramp proteins form in each case a single cluster or, in the case of $A$. thaliana, two different, but very closely related clusters. It has been suggested that Nramp proteins originated in prokaryotes and were transferred endosymbiotically to the eukaryotic nucleus. Horizontal gene transfer from eukaryotes to prokaryotes has also been hypothesized to justify unexpected sequence diversity in $\mathrm{MntH}$ phyletic groups (Richer et al., 2003), and could explain the surprisingly closer similarity of Dictyostelid Nramp2 to $\alpha$-proteobacterial homologs than to other bacterial MntH sequences. If the Slc11 Nramp family derived from a duplication from an ancient Nramp, as is likely (Richer et al., 2003), then Dictyostelium offers a unique opportunity to study the evolutionary divergence of these two types of Nramp proteins coexisting in a single organism.

The cellular localization of the Nramp1 and Nramp2 is very different. Like mammalian Nramp1, Dictyostelium Nramp1 shuttles from the Golgi to the endolysosomal pathway, being recruited to phagosomes and macropinosomes shortly after their closure and recruitment of the $\mathrm{V}-\mathrm{H}^{+}$-ATPase. Colocalization of $\mathrm{V}-\mathrm{H}^{+}$-ATPase and Nramp1 in the membrane generates the right conditions for proton-driven transport of iron and other metals from such vesicles to the cytosol, exactly as occurs for vertebrate Nramp1 (Courville et al., 2006; Peracino et al., 2006). Nramp2 is instead expressed selectively in the membrane of the contractile vacuole network, which regulates osmolarity. As soil amoebae living in the forest Dictyostelium cells are exposed to sudden changes of osmotic conditions, so that water regulation is critical for their survival. The contractile bladder and tubular network fills with water and swells under hypoosmotic conditions, giving rise to larger vacuoles that fuse with the plasma membrane to discharge excess fluid. Under hyperosmotic conditions, the cisternae flatten and the tubules get narrow (Clarke and Heuser, 1997; Gerisch et al., 2002; Heuser et al., 1993). With a functioning $\mathrm{CV}$, cells submerged in water survive, acquire the typical amoeboid shape and can also undergo development, whereas they rapidly round up and lyse if the CV cannot fulfil its function (Du et al., 2008; Gerald et al., 2002; Myre et al., 2011). The CV membrane is studded with vacuolar $\mathrm{H}^{+}$-ATPase, which pumps protons into the lumen. Cells possess also a cytoplasmic carboanhydrase and a bicarbonate transporter in the $\mathrm{CV}$ membrane (Giglione and Gross, 1995; Heuser et al., 1993). It has been suggested that production of bicarbonate from $\mathrm{CO}_{2}$ by the carbonic anhydrase and cotransport of the anion with protons into the lumen of the $\mathrm{CV}$ generate osmotically active carbonic acid that could draw water into the vacuole (Clarke and Heuser, 1997; Heuser et al., 1993).

The finding that $\mathrm{V}-\mathrm{H}^{+}$-ATPase and Nramp2 co-localize in the $\mathrm{CV}$ membrane is suggestive of a potential role of the contractile vacuole in homeostasis of iron, and possibly other divalent metals. In the wild the major source of iron for Dictyostelium cells is very likely the engulfed bacteria. We propose that iron, released after phagocytosis and digestion of bacteria (or ingested with peptone and yeast extract by macropinocytosis, in the case of laboratory axenic strains) is reduced to $\mathrm{Fe}^{2+}$ in phago- or macropinolysosomes and transported via Nramp1 to the cytosol, where it can be used for cellular functions. Excess free iron could be transported in the CV that could thus function as a store or sink for the labile iron pool. The colocalization of Nramp1 or Nramp2 with the $\mathrm{V}-\mathrm{H}^{+}$-ATPase in phagolysosomes or the contractile vacuole, respectively, could explain vectorial transport by a common mechanism, namely electrogenic potential driven by the proton pump (Fig. 8). It is established for mammalian Nramp1 and Nramp2 (Courville et al., 2006), Dictyostelium Nramp1 (Peracino et al., 2006), and for bacterial and yeast homologs of Dictyostelium Nramp2 (Courville et al., 2006), that the proton gradient generated by the vacuolar ATPase favors iron export from vesicles, such as phagolysosomes or yeast vacuoles, via Nramp. In the case of Dictyostelium Nramp2, this mechanism of action would imply iron efflux from the contractile vacuole into the cytosol (Fig. 8). One objection to this mechanism is that the $\mathrm{pH}$ in the $\mathrm{CV}$ lumen is neutral, possibly due to proton buffering by cotransported bicarbonate (Clarke and Heuser, 1997; Giglione and Gross, 1995). It is possible however that a slight $\Delta \mathrm{pH}$ across the $\mathrm{CV}$ membrane is present, which could be sufficient for iron efflux via Nramp2. In this context it is worth mentioning that a P-type $\mathrm{Ca}^{2+}$ ATPase (PAT1) is also localized to the $\mathrm{CV}$ and is involved in $\mathrm{V}-\mathrm{H}^{+}$-ATPase-dependent $\mathrm{Ca}^{2+}$ sequestration (Moniakis et al., 1999), as well as efflux to the cytoplasm, although it is unclear how the latter is regulated 


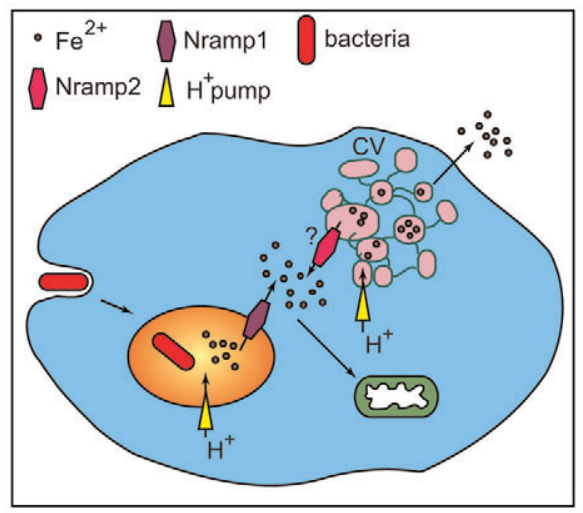

Fig. 8. Model for the function of Nramp1 and Nramp2 and of the contractile vacuole (CV) in iron homeostasis. Nramp1 is recruited to phagosomes after bacterial uptake and recruitment of the $\mathrm{V}-\mathrm{H}^{+}$-ATPase to the phagosomes, whereas Nramp2 and the $\mathrm{V}-\mathrm{H}^{+}$-ATPase are resident proteins of the $\mathrm{CV}$ network. Acidification by the $\mathrm{V}-\mathrm{H}^{+}$-ATPase leads to a proton gradient in the phagosome that favors cotransport to the cytosol of ferrous ions deriving from bacterial degradation (or digestion of peptone and yeast extract in case of growth in axenic medium). Iron is required for cellular functions, particularly in mitochondria. We suggest that the contractile vacuole act as a store/sink for labile iron, with sporadic or induced CV fusion with the plasma membrane leading to iron excretion. Iron can be transported across the $\mathrm{CV}$ membrane via Nramp2, and the directionality of this transport is regulated by the $\mathrm{V}-\mathrm{H}^{+}$-ATPase, which can provide the electrogenic potential across the membrane for iron influx into the cytosol, similar to what occurs in the phagosome. It is worth mentioning however that the $\mathrm{pH}$ in the $\mathrm{CV}$ lumen is mostly neutral (Giglione and Gross, 1995), therefore it is open to what extent this mechanism is constitutively active or efficient.

(Malchow et al., 2006). In any case a role for Nramp2 in mobilizing iron from the contractile vacuole is suggested by the iron-limited growth as well as the developmental delay of the nramp2-null mutant. If the model in Fig. 8 is correct, it can be speculated that Dictyostelium Nramp2 plays a role similar to the Nramp homologs in yeast (SMF3) or A. thaliana (AtNramp3 and AtNramp4), which mobilize iron from their respective vacuoles (Portnoy et al., 2000; Lanquar et al., 2005).

We have shown that disrupting nramp1, nramp 2 or both has pleiotropic effects on development, cell growth under iron overload or shortage and on resistance to L. pneumophila. The developmental phenotypes are more difficult to correlate with specific defects in iron homeostasis, as very little is known in this regard in Dictyostelium. Development occurs in a simple salt solution made of $\mathrm{Na}$ - and K-phosphate, and can also occur in water. Exogenous iron or other metals are not essential, thus iron that is certainly required for mitochondrial activity and other iron-linked enzymatic activities is all fuelled by endogenous store. It is of interest that Nramp1 gene expression is downregulated during development, whereas Nramp2 expression is upregulated during the first 6 hours of development, coincident with the aggregation stage, and downregulated after formation of tight aggregates. Consistent with this regulation, Nramp1 gene disruption has little effect on development, resulting only in a slight acceleration of development, whereas inactivating Nramp2 delays the beginning of aggregation by 2 hours. Inactivating both genes results in a much stronger delay in cell aggregation, in large streaming aggregates and multitipped mounds. Despite fragmentation following multitip formation, fewer but on average taller fruiting bodies are formed in the double mutant compared to the parental strain. This phenotype can be explained by assuming that development of the aggregation competence is inhibited in the double mutant, such that fewer cells in the population are able to initiate autonomous cell-cell signaling that is required for chemotaxis and aggregation. It can be speculated that altered iron homeostasis affects mitochondrial activity which is necessary for proceeding in development. It is worth mentioning that starvation induces upregulation of mitochondrial enzymes, such as the citrate synthase. In addition, many Krebs cycle as well as oxidative phosphorylation enzymes and the iron-sensing aconitate hydratase are strongly upregulated during stream formation and aggregation up to the mound stage (Czarna et al., 2010). Thus, reduced mitochondrial efficiency, as a consequence of defective iron storage during growth and/or mobilization during development, could explain the delay of the single Nramp2 mutant and the developmental phenotype of the double mutant. It is suggestive that large streams and multitipped aggregates are also a common phenotype of autophagy mutants (Otto et al., 2003; Tung et al., 2010). Defective autophagy could also result in altered oxidative phosphorylation, as autophagy is required for recycling of intracellular components during Dictyostelium development (Otto et al., 2003).

The major effect of nrampl inactivation is increased susceptibility to infection by $L$. pneumophila and $M$. avium (Peracino et al., 2006), resembling in this regard the effects of mutated mammalian Nramp1 (Cellier et al., 2007). Inactivating nramp 2 or both genes also leads to increased sensitivity to Legionella infection compared to the parental strain, with the double mutant being very likely more affected, although this was not reflected in increased bacterial proliferation when measured by the CFU method. As mentioned in the results, this may be due to the CFU assay measuring bacteria that were viable at the time of the assay and not bacteria that had been released prior to the assay but subsequently died in the inhospitable culture medium. Thus it appears that any alteration of iron homeostasis via Nramp1 or Nramp2 disruption facilitates intracellular growth of Legionella. Whether this holds true also for M. avium is currently under study. In the absence of Nramp1, iron export from phagosomes or macropinosomes is strongly reduced (Peracino et al., 2006), thus it is conceivable that disruption of the nrampl gene will lead to increased iron accumulation in the Legionellacontaining macropinosome, a condition favoring Legionella growth (Robey and Cianciotto, 2002). How can inactivation of Nramp2, which is localized in the contractile vacuole, have a similar effect, if Nramp1 is active? We have recently shown that Legionella effectively hinders recruitment of the $\mathrm{V}-\mathrm{H}^{+}$-ATPase, but not Nramp1, to the Legionella-containing macropinosome (Peracino et al., 2010). In the absence of the vacuolar ATPase, Nramp1 pumping activity is neutralized, and iron may be sequestered by the Legionella (Peracino et al., 2006). Under these conditions, if Nramp2 is not functioning it is possible that cytosolic iron deficiency may affect basic cell functions, favoring Legionella growth.

In contrast to pathogens, non-pathogenic bacteria, such as $E$. coli, are taken up and digested at about the same rate by the mutants as well as the parental strain. Cell growth in either axenic medium, presumably containing about $0.05 \mathrm{mM} \mathrm{Fe}$ (Franke and Kessin, 1977), or minimal medium supplemented with 0.01 to 
$0.1 \mathrm{mM}$ iron chloride, is also not dramatically affected by nramp 1 or nramp 2 gene inactivation. In contrast, the single and double mutants are much more sensitive than the wild type strain to iron depletion and less sensitive, particularly the double mutant, to iron overload. Both results are consistent with the assumption that inactivating Nramp1, Nramp2 or both leads to lower accumulation of cytosolic iron, decreasing iron availability for cellular functions. As a consequence, when shifted from axenic medium to conditions of iron shortage the mutant cells deplete their free iron reserves more rapidly and stop growing after 1-2 duplications, whereas the parental wild type strain is able to sustain about 5-6 duplication rounds. In the case of iron overload, growth is strongly reduced in all strains, but the double mutant is more resistant to excess iron than the wild type strain and is able to grow, albeit slowly. Indeed, under the experimental conditions of this study most iron is very likely taken up via macropinocytosis, a process that is not affected by disruption of nramp1 or nramp2. However, Nramp1 loss is expected to strongly reduce iron release from the macropinosomes to the cytosol, as iron transport across the phagosomal membrane was found to be inhibited in nrampl-KO mutant (Peracino et al., 2006). In contrast to many mammalian cells, in Dictyostelium the endolysosomes are not the dead-end of endosomal traffic. Instead they mature into neutral post-lysosomal vesicles that fuse with the plasma membrane, releasing their contents. Thus, if Nramp1 is inactive, iron will remain in large part entrapped in macropinosomes and could be excreted. This can explain the phenotype of both the single Nramp1 and the double Nramp1/ Nramp2 KO mutant. The higher resistance of the latter to iron overload, compared to the parental AX2 strain and to the single mutants, could depend both on less iron leaking from macropinosomes and from the contractile vacuole, due to absence of Nramp1 and Nramp2. However, disruption of both genes may also affect expression of other potential regulators of iron homeostasis, such as ferritin-like proteins, which appear to be encoded in the Dictyostelium genome. Cloning and analysis of these genes will be required for a better understanding of iron homeostasis in Dictyostelium.

In summary, the described phenotypes can be explained by the model presented in Fig. 8, according to which Nramp1 and Nramp2, due to their conserved function, distinct intracellular location and to colocalization with the vacuolar ATPase, synergistically regulate proton-driven iron transport across the phagosomal/macropinosomal membrane and the membrane of the contractile vacuole.

\section{Material and Methods}

Cell and bacterial strains and culture methods

Dictyostelium discoideum parental strain AX2 was used. The Nramp1-null mutan HSB60 and AX2 cells expressing Nramp1-GFP had been generated previously (Peracino et al., 2006).

All strains were cultured axenically in either AX2 medium (Watts and Ashworth, 1970) or minimal medium (Franke and Kessin, 1977), with or without $\mathrm{FeCl}_{3}$. In both cases, cells were grown in Erlenmayer flasks at $23^{\circ} \mathrm{C}$ under shaking at 150 r.p.m. on a gyratory shaker in a climatic cabinet (Kuehner, Basel, Switzerland) as described (Bussolino et al., 1991). Blasticidin at a concentration of $10 \mu \mathrm{g} / \mathrm{ml}$ was added to knockout mutants. Cells expressing GFP-fused proteins were cultured in the presence of 10 or $20 \mu \mathrm{g} / \mathrm{ml} \mathrm{G} 418$.

For growth and development on nutrient agar, cells were mixed with Escherichia coli $\mathrm{B} / 2$, plated on nutrient agar plates containing peptone and glucose in Soerensen phosphate buffer and incubated at $23^{\circ} \mathrm{C}$ (Sillo et al., 2008). Growth and development were observed in a Wild M3Z stereomicroscope and pictures were taken with a Bresser PC-Microcular 3.0 MP webcam connected to a PC-computer, using Webcam Companion 1 software.
Legionella pneumophila Corby expressing GFP was grown on buffered charcoal yeast extract agar (BYCE) containing $5 \mu \mathrm{g} / \mathrm{ml}$ chloramphenicol and incubated for 72 hours at $37^{\circ} \mathrm{C}$ and $5 \% \mathrm{CO} 2$ (Fajardo et al., 2004).

\section{Cell development on non-nutrient agar plates}

For synchronizing development, exponentially growing cells were harvested from culture medium, washed twice in $0.017 \mathrm{M}$ Soerensen $\mathrm{Na} / \mathrm{K}$ phosphate buffer, pH 6.0 and resuspended in the same buffer at a concentration of $1 \times 10^{7}$ per ml. Aliquots of $0.05 \mathrm{ml}$ were plated on agar plates buffered with Soerensen phosphate buffer at a density of about $3 \times 10^{5}$ cells per $\mathrm{cm}^{2}$, and incubated at $23^{\circ} \mathrm{C}$ (Bozzaro et al., 1987).

\section{Infection assays with L. pneumophila}

Exponentially growing AX2 and mutant cells were washed, incubated in AX2 medium without maltose and aliquots of $1 \times 10^{5}$ cells were plated in 96-well tissue culture plates. Freshly collected L. pneumophila were added at a MOI of $1: 1$ and immediately centrifuged at $600 \mathrm{~g}$ for $10 \mathrm{~min}$ at room temperature to synchronize infection. The number of viable bacteria was calculated by counting the colony forming units (CFU) per $\mathrm{ml}$ immediately after centrifugation and during the subsequent 96 hours (Bozzaro et al., 2012).

\section{Gene cloning, vector construction for GFP expression and} cell transformation

The nramp 2 gene (DDB_G0275815) was cloned starting from the genomic DNA fragment JC2a11a12 amplified with appropriate primers and cloned in pGEMTEasy (Promega, Madison, WI, USA), according to Sambrook et al. (Sambrook et al., 1989). For fusion with GFP, the Nramp2-coding sequence was amplified from pGEM-Teasy-Nramp2 and inserted into the EcoRI site of the pDEX-GFPC vector with Nramp2(C) connected to S65T-GFP by the linker EFKKLK (Westphal et al., 1997). Cell transformation was done by electroporation (Pang et al., 1999) and transformants were selected on plates with nutrient medium containing $10 \mu \mathrm{g}$ / $\mathrm{ml} \mathrm{G418.}$

\section{Construction of single nramp2 and double nramp1/2 knockout mutants} The blasticidin cassette was excised from the pLPBLP(floxed Bsr) vector (Faix et al., 2004) in SmaI, purified and inserted in the single EcoRV site of the Nramp gene in pGEM-TEasy-Nramp2. The vector carrying the selectable marker was linearized from the pGEM-TEasy vector with EcoRI, purified and electroporated in AX2 cells. The transformed cell population was splitted in 96-well plates and grown in the presence of $10 \mu \mathrm{g} / \mathrm{ml}$ of blasticidin. Resistant clones were screened by PCR using appropriate primers. Positive clones were subject to Southern blot analysis as described (Bracco et al., 1997). After a preliminary phenotypic analysis of three clones, one clone was treated with pDEX-NLS-cre to transiently express the CRE recombinase and remove the blasticidin cassette (Kimmel and Faix, 2006). To generate the double mutant, one clone was further transformed with the linearized Nramp1 gene containing the bsr cassette from the Nramp1-KO vector (Peracino et al., 2006). Clones were analyzed by PCR and positive ones further confirmed by Southern blot analysis.

\section{Gene expression analysis by quantitative PCR}

Total RNA was extracted with TRIzol, according to manufacturer instructions (Invitrogen, Carlsbad, CA, USA) from cells at different developmental times and analyzed by quantitative PCR The RNA was treated with Dnase and retrotranscribed with random hexamer primers and Multiscribe Reverse transcriptase (High Capacity cDNA Archive Kit; Applied Biosystems, Foster City, CA), in accordance with manufacturer's instructions. Expression levels of nramp1, nramp2 and reference histone $\mathrm{H} 3$ were evaluated with SYBR technology with optimized PCR conditions and primer concentrations. Primer sequences were as follows: nrampl FW: CATCGGCTGCTGATTTCCTTAT, nrampl RW ATAAACCGATTGCCCAAATGTATT; nramp2 FW: CGAGGTTTTCTCTGGTTTCG, nramp2 RW: CCAACGATGCCAGTTGCA, H3 FW: CGCACGTAAATCAACTGGTG, $H 3$ RW: GGAAACGAAGATCGGTTTTG. Melting curve analysis and efficiency evaluation were performed for all the amplicons. Quantitative PCR (qPCR) was carried-out on an ABI PRISM 7900HT Sequence Detection System (Applied Biosystems) in 384-well plates assembled by Biorobot 8000 (Qiagen, Germantown, ML, USA). Baselines and thresholds for Ct calculation were set up manually with the ABI Prism SDS 2.1 software.

\section{In vivo microscopy, fluorescence imaging and immunofluorescence}

Living cells expressing Nramp1(C)- or Nramp2(C)-GFP were incubated with $1 \mathrm{mg} / \mathrm{ml} \mathrm{TRITC-dextran}$ for $5 \mathrm{~min}$ under shaking, washed and plated on $6 \times 6 \mathrm{~cm}$ glass coverslip equipped with a $5-\mathrm{cm}$ diameter Plexiglas ring. For staining acidic vesicles, cells were incubated with $0.1 \mu \mathrm{M}$ Neutral Red. Confocal series images were taken on an inverted Zeiss LSM510 microscope as described (Peracino et al., 2006). For immunofluorescence studies, cells were fixed with cold methanol, incubated with antibodies against the $\mathrm{V}-\mathrm{H}^{+}$-ATPase subunit vatA and mounted with Gelvatol as described (Peracino et al., 1998). TRITC-labeled goat anti-mouse 
(Jackson ImmunoResearch, West Grove, PA, USA) was used as secondary antibody.

\section{Acknowledgements}

We thank Hans Faix for the pLPBLP(floxed Bsr) and pDEX-NLScre plasmids, Gernot Gloeckner for DNA clone JC2a11a12 and Markus Maniak for anti-vatA antibody. We also acknowledge Marco Lo Iacono help with qPCR and Paul Fisher for critical reading of the manuscript.

\section{Funding}

The work was supported by funds of the Region Piemonte and the University of Turin.

\section{Supplementary material available online at}

http://jcs.biologists.org/lookup/suppl/doi:10.1242/jcs.116210/-/DC1

\section{References}

Bozzaro, S. and Eichinger, L. (2011). The professional phagocyte Dictyostelium discoideum as a model host for bacterial pathogens. Curr. Drug Targets 12, 942-954.

Bozzaro, S., Merkl, R. and Gerisch, G. (1987). Cell adhesion: its quantification, assay of the molecules involved, and selection of defective mutants in Dictvostelium and Polysphondylium. Methods Cell Biol. 28, 359-385. 2013

Bozzaro, S., Bucci, C. and Steinert, M. (2008). Phagocytosis and nost-patnogen interactions in Dictyostelium with a look at macrophages. Int. Rev. Cell. Mol. Biol. 271, 253-300

Bozzaro, S., Peracino, B. and Eichinger, L. (2012). Dictyostelium 1005 Legionella infection: strategies and assays. Methods Mol. Biol. 2013, 417-438.

Bracco, E., Peracino, B., Noegel, A. A. and Bozzaro, S. (1997). Cloning and transcriptional regulation of the gene encoding the vacuolar/H+ ATPase B subunit of Dictyostelium discoideum. FEBS Lett. 419, 37-40.

Bussolino, F., Sordano, C., Benfenati, E. and Bozzaro, S. (1991). Dictyostelium cells produce platelet-activating factor in response to cAMP. Eur. J. Biochem. 196, 609615

Canonne-Hergaux, F. and Gros, P. (2004). Tissue distribution and subcellular localization of Nramp proteins. In The Nramp Family (ed. M. F. Cellier and P. Gros), pp. 96-112. New York, NY: Kluwer Academic Publishers.

Canonne-Hergaux, F., Gruenheid, S., Ponka, P. and Gros, P. (1999). Cellular and subcellular localization of the Nramp2 iron transporter in the intestinal brush border and regulation by dietary iron. Blood $\mathbf{9 3}, 4406-4417$.

Cellier, M. F., Courville, P. and Campion, C. (2007). Nramp1 phagocyte intracellular metal withdrawal defense. Microbes Infect. 9, 1662-1670.

Chen, G., Zhuchenko, O. and Kuspa, A. (2007). Immune-like phagocyte activity in the social amoeba. Science 317, 678-681.

Clarke, M. and Heuser, J. (1997). Water and ion transport. In Dictyostelium - A Model System for Cell and Developmental Biology (ed. Y. Maeda, K. Inouye and I. Takeuchi), pp. 75-91. Tokyo, Japan: Universal Academy Press.

Clarke, M., Köhler, J., Arana, Q., Liu, T. Y., Heuser, J. and Gerisch, G. (2002). Dynamics of the vacuolar H(+)-ATPase in the contractile vacuole complex and the endosomal pathway of Dictyostelium cells. J. Cell Sci. 115, 2893-2905.

Clarke, M., Maddera, L., Engel, U. and Gerisch, G. (2010). Retrieval of the vacuolar H-ATPase from phagosomes revealed by live cell imaging. PLOS ONE 5, e8585.

Colucci, A. M., Peracino, B., Tala, A., Bozzaro, S., Alifano, P. and Bucci, C. (2008) Dictyostelium discoideum as a model host for meningococcal pathogenesis. Med. Sci. Monit. 14, BR134-BR140.

Cosson, P. and Soldati, T. (2008). Eat, kill or die: when amoeba meets bacteria. Curr. Opin. Microbiol. 11, 271-276.

Courville, P., Chaloupka, R. and Cellier, M. F. (2006). Recent progress in structurefunction analyses of Nramp proton-dependent metal-ion transporters. Biochem. Cell Biol. 84, 960-978.

Czachorowski, M., Lam-Yuk-Tseung, S., Cellier, M. and Gros, P. (2009). Transmembrane topology of the mammalian Slc11a2 iron transporter. Biochemistry 48, 8422-8434

Czarna, M., Mathy, G., Mac'Cord, A., Dobson, R., Jarmuszkiewicz, W., SluseGoffart, C. M., Leprince, P., De Pauw, E. and Sluse, F. E. (2010). Dynamics of the Dictyostelium discoideum mitochondrial proteome during vegetative growth, starvation and early stages of development. Proteomics 10, 6-22.

Du, F., Edwards, K., Shen, Z., Sun, B., De Lozanne, A., Briggs, S. and Firtel, R. A. (2008). Regulation of contractile vacuole formation and activity in Dictyostelium. EMBO J. 27, 2064-2076.

Faix, J., Kreppel, L., Shaulsky, G., Schleicher, M. and Kimmel, A. R. (2004). A rapid and efficient method to generate multiple gene disruptions in Dictyostelium discoideum using a single selectable marker and the Cre-loxP system. Nucleic Acids Res. 32, e143.

Fajardo, M., Schleicher, M., Noegel, A., Bozzaro, S., Killinger, S., Heuner, K., Hacker, J. and Steinert, M. (2004). Calnexin, calreticulin and cytoskeletonassociated proteins modulate uptake and growth of Legionella pneumophila in Dictyostelium discoideum. Microbiology 150, 2825-2835.
Fleming, M. D., Trenor, C. C., 3rd, Su, M. A., Foernzler, D., Beier, D. R., Dietrich, W. F. and Andrews, N. C. (1997). Microcytic anaemia mice have a mutation in Nramp2, a candidate iron transporter gene. Nat. Genet. 16, 383-386.

Forbes, J. R. and Gros, P. (2001). Divalent-metal transport by NRAMP proteins at the interface of host-pathogen interactions. Trends Microbiol. 9, 397-403.

Franke, J. and Kessin, R. (1977). A defined minimal medium for axenic strains of Dictyostelium discoideum. Proc. Natl. Acad. Sci. USA 74, 2157-2161.

Gerald, N. J., Siano, M. and De Lozanne, A. (2002). The Dictyostelium LvsA protein is localized on the contractile vacuole and is required for osmoregulation. Traffic $\mathbf{3}$, $50-60$

Gerisch, G., Heuser, J. and Clarke, M. (2002). Tubular-vesicular transformation in the contractile vacuole system of Dictyostelium. Cell Biol. Int. 26, 845-852.

Giglione, C. and Gross, J. D. (1995). Anion effects on vesicle acidification in Dictyostelium. Biochem. Mol. Biol. Int. 36, 1057-1065.

Gruenheid, S., Pinner, E., Desjardins, M. and Gros, P. (1997). Natural resistance to infection with intracellular pathogens: the Nramp1 protein is recruited to the membrane of the phagosome. J. Exp. Med. 185, 717-730.

Gunshin, H., Fujiwara, Y., Custodio, A. O., Direnzo, C., Robine, S. and Andrews, N. C. (2005). Slc11a2 is required for intestinal iron absorption and erythropoiesis but dispensable in placenta and liver. J. Clin. Invest. 115, 1258-1266.

Hagedorn, M., Rohde, K. H., Russell, D. G. and Soldati, T. (2009). Infection by tubercular mycobacteria is spread by nonlytic ejection from their amoeba hosts. Science 323, 1729-1733

Hägele, S., Köhler, R., Merkert, H., Schleicher, M., Hacker, J. and Steinert, M. (2000). Dictyostelium discoideum: a new host model system for intracellular pathogens of the genus Legionella. Cell. Microbiol. 2, 165-171.

Henard, C. and Vazquez-Torres, A. (2011). Nitric oxide and Salmonella pathogenesis. Front. Microbiol 2, DOI=10.3389/fmicb.2011.00084.

Hentze, M. W., Muckenthaler, M. U., Galy, B. and Camaschella, C. (2010). Two to tango: regulation of Mammalian iron metabolism. Cell 142, 24-38.

Heuser, J., Zhu, Q. L. and Clarke, M. (1993). Proton pumps populate the contractile vacuoles of Dictyostelium amoebae. J. Cell Biol. 121, 1311-1327.

Iolascon, A. and De Falco, L. (2009). Mutations in the gene encoding DMT1: clinical presentation and treatment. Semin. Hematol. 46, 358-370.

Johnson, E. E. and Wessling-Resnick, M. (2012). Iron metabolism and the innate immune response to infection. Microbes Infect. 14, 207-216.

Kakhlon, O. and Cabantchik, Z. I. (2002). The labile iron pool: characterization, measurement, and participation in cellular processes(1). Free Radic. Biol. Med. 33, 1037-1046.

Kessin, R. H. (2001). Dictyostelium - Evolution, Cell Biology and the Development of Multicellularity. Cambridge, UK: Cambridge University Press.

Kimmel, A. R. and Faix, J. (2006). Generation of multiple knockout mutants using the Cre-loxP system. Methods Mol. Biol. 346, 187-199.

Kortman, G. A., Boleij, A., Swinkels, D. W. and Tjalsma, H. (2012). Iron availability increases the pathogenic potential of Salmonella typhimurium and other enteric pathogens at the intestinal epithelial interface. PLOS ONE 7, e29968.

Lam-Yuk-Tseung, S. and Gros, P. (2006). Distinct targeting and recycling properties of two isoforms of the iron transporter DMT1 (NRAMP2, Slc11A2). Biochemistry 45, 2294-2301.

Lanquar, V., Lelièvre, F., Bolte, S., Hamès, C., Alcon, C., Neumann, D., Vansuyt, G., Curie, C., Schröder, A., Krämer, U. et al. (2005). Mobilization of vacuolar iron by AtNRAMP3 and AtNRAMP4 is essential for seed germination on low iron. EMBO J. 24, 4041-4051

Li, X., Yang, Y., Zhou, F., Zhang, Y., Lu, H., Jin, Q. and Gao, L. (2011). SLC11A1 (NRAMP1) polymorphisms and tuberculosis susceptibility: updated systematic review and meta-analysis. PLOS ONE 6, e15831.

Lima, W. C., Lelong, E. and Cosson, P. (2011). What can Dictyostelium bring to the study of Pseudomonas infections? Semin. Cell Dev. Biol. 22, 77-81.

Malchow, D., Lusche, D. F., Schlatterer, C., De Lozanne, A. and MüllerTaubenberger, A. (2006). The contractile vacuole in Ca2+-regulation in Dictyostelium: its essential function for cAMP-induced Ca2+-influx. BMC Dev. Biol. 6, 31-39.

Malik, S., Abel, L., Tooker, H., Poon, A., Simkin, L., Girard, M., Adams, G. J., Starke, J. R., Smith, K. C., Graviss, E. A. et al. (2005). Alleles of the NRAMP1 gene are risk factors for pediatric tuberculosis disease. Proc. Natl. Acad. Sci. USA 102, 12183-12188.

Moalem, S., Weinberg, E. D. and Percy, M. E. (2004). Hemochromatosis and the enigma of misplaced iron: implications for infectious disease and survival. Biometals 17, 135-139.

Moniakis, J., Coukell, M. B. and Janiec, A. (1999). Involvement of the Ca2+-ATPase PAT1 and the contractile vacuole in calcium regulation in Dictyostelium discoideum. J. Cell Sci. 112, 405-414.

Myre, M. A., Lumsden, A. L., Thompson, M. N., Wasco, W., MacDonald, M. E. and Gusella, J. F. (2011). Deficiency of huntingtin has pleiotropic effects in the social amoeba Dictyostelium discoideum. PLoS Genet. 7, e1002052.

Nevo, Y. and Nelson, N. (2006). The NRAMP family of metal-ion transporters. Biochim. Biophys. Acta 1763, 609-620.

Otto, G. P., Wu, M. Y., Kazgan, N., Anderson, O. R. and Kessin, R. H. (2003). Macroautophagy is required for multicellular development of the social amoeba Dictyostelium discoideum. J. Biol. Chem. 278, 17636-17645.

Pang, K. M., Lynes, M. A. and Knecht, D. A. (1999). Variables controlling the expression level of exogenous genes in Dictyostelium. Plasmid 41, 187-197. 
Papp-Wallace, K. M. and Maguire, M. E. (2006). Manganese transport and the role of manganese in virulence. Annu. Rev. Microbiol. 60, 187-209.

Peracino, B., Borleis, J., Jin, T., Westphal, M., Schwartz, J. M., Wu, L. J., Bracco, E., Gerisch, G., Devreotes, P. and Bozzaro, S. (1998). G protein beta subunit-null mutants are impaired in phagocytosis and chemotaxis due to inappropriate regulation of the actin cytoskeleton. J. Cell Biol. 141, 1529-1537.

Peracino, B., Wagner, C., Balest, A., Balbo, A., Pergolizzi, B., Noegel, A. A. Steinert, M. and Bozzaro, S. (2006). Function and mechanism of action of Dictyostelium Nramp1 (Slc11a1) in bacterial infection. Traffic 7, 22-38.

Peracino, B., Balest, A. and Bozzaro, S. (2010). Phosphoinositides differentially regulate bacterial uptake and Nramp1-induced resistance to Legionella infection in Dictyostelium. J. Cell Sci. 123, 4039-4051.

Portnoy, M. E., Liu, X. F. and Culotta, V. C. (2000). Saccharomyces cerevisiae expresses three functionally distinct homologues of the nramp family of metal transporters. Mol. Cell. Biol. 20, 7893-7902.

Richer, E., Courville, P., Bergevin, I. and Cellier, M. F. (2003). Horizontal gene transfer of "prototype" Nramp in bacteria. J. Mol. Evol. 57, 363-376.

Robey, M. and Cianciotto, N. P. (2002). Legionella pneumophila feoAB promotes ferrous iron uptake and intracellular infection. Infect. Immun. 70, 5659-5669.

Sambrook, J., Maniatis, T. and Fritsch, E. (1989). Molecular Cloning: A Laboratory Manual. Cold Spring Harbor, NY: Cold Spring Harbor Laboratory Press.

Schaible, U. E. and Kaufmann, S. H. (2004). Iron and microbial infection. Nat. Rev. Microbiol. 2, 946-953.

Sillo, A., Bloomfield, G., Balest, A., Balbo, A., Pergolizzi, B., Peracino, B., Skelton, J., Ivens, A. and Bozzaro, S. (2008). Genome-wide transcriptional changes induced by phagocytosis or growth on bacteria in Dictyostelium. BMC Genomics 9, 291.

Sillo, A., Matthias, J., Konertz, R., Bozzaro, S. and Eichinger, L. (2011). Salmonella typhimurium is pathogenic for Dictyostelium cells and subverts the starvation response. Cell. Microbiol. 13, 1793-1811.
Slauch, J. M. (2011). How does the oxidative burst of macrophages kill bacteria? Still an open question. Mol. Microbiol. 80, 580-583.

Soe-Lin, S., Apte, S. S., Mikhael, M. R., Kayembe, L. K., Nie, G. and Ponka, P. (2010). Both Nramp1 and DMT1 are necessary for efficient macrophage iron recycling. Exp. Hematol. 38, 609-617.

Steinert, M. (2011). Pathogen-host interactions in Dictyostelium, Legionella, Mycobacterium and other pathogens. Semin. Cell Dev. Biol. 22, 70-76.

Taylor, M. C. and Kelly, J. M. (2010). Iron metabolism in trypanosomatids, and its crucial role in infection. Parasitology 137, 899-917.

Theil, E. C. (2011). Iron homeostasis and nutritional iron deficiency. J. Nutr. 141, 724S$728 \mathrm{~S}$

Tung, S. M., Unal, C., Ley, A., Peña, C., Tunggal, B., Noegel, A. A., Krut, O., Steinert, M. and Eichinger, L. (2010). Loss of Dictyostelium ATG9 results in a pleiotropic phenotype affecting growth, development, phagocytosis and clearance and replication of Legionella pneumophila. Cell. Microbiol. 12, 765-780.

Velez, D. R., Hulme, W. F., Myers, J. L., Stryjewski, M. E., Abbate, E., Estevan, R. Patillo, S. G., Gilbert, J. R., Hamilton, C. D. and Scott, W. K. (2009). Association of SLC11A1 with tuberculosis and interactions with NOS2A and TLR2 in AfricanAmericans and Caucasians. Int. J. Tuberc. Lung Dis. 13, 1068-1076.

Watts, D. J. and Ashworth, J. M. (1970). Growth of myxameobae of the cellular slime mould Dictyostelium discoideum in axenic culture. Biochem. J. 119, 171-174.

Westphal, M., Jungbluth, A., Heidecker, M., Mühlbauer, B., Heizer, C., Schwartz, J. M., Marriott, G. and Gerisch, G. (1997). Microfilament dynamics during cell movement and chemotaxis monitored using a GFP-actin fusion protein. Curr. Biol. 7 , 176-183.

Wick, M. J. (2011). Innate immune control of Salmonella enterica serovar Typhimurium: mechanisms contributing to combating systemic Salmonella infection. J. Innate Immun. 3, 543-549. 